\title{
The eye drop chart: a pilot study for improving administration of and compliance with topical treatments in glaucoma patients
}

This article was published in the following Dove Press journal:

Clinical Ophthalmology

5 May 2015

Number of times this article has been viewed

\author{
Katherine Anne McVeigh' \\ Georgios Vakros ${ }^{2}$ \\ 'Department of Ophthalmology, Royal \\ United Hospital, Combe Park, Bath, \\ UK; ${ }^{2}$ Department of Ophthalmology, \\ Queen's Hospital, Romford, Essex, UK
}

Aim: In order to improve patient education, compliance, and administration of eye drops prescribed for patients suffering with glaucoma within a UK ophthalmology department, an eye drop chart (EDC) was designed, developed, and piloted with patients attending the glaucoma clinic over 1 month.

Methods: A cross-sectional prospective pilot study of 25 patients using an administration aid and a self-reported questionnaire. Chi-square tests were used to compare responses pre- and postintervention.

Results: Results demonstrated an impressive improvement in nine of eleven categories assessed regarding drop administration and compliance. Patients stating that they always wash their hands increased significantly from $64 \%$ (13 participants) to $92 \%$ (23 participants) $(P=0.029)$, and those who always shake the bottle improved from $40 \%$ (10) to $84 \%(21)(P=0.001)$. Punctal occlusion techniques improved from $44 \%(11)$ to $72 \%(18)(P=0.015)$. Finally, patients who always discarded the bottle after 28 days of use rose from $68 \%$ to $92 \%$, though the difference was not significant $(P=0.09)$. Only the number of drops being administered to the eye and the length of time left between the application of drops remained relatively unchanged. Sixty-four percent reported finding EDC helpful or useful, 52\% had positive responses when asked if they would continue using EDC, and $88 \%$ would recommend it to a friend.

Conclusion: Although there are limitations to the data as they are subjective, descriptive, and limited to sample size of 25 , the results of this pilot study have shown promise. The EDC appears to be a cost-effective way at improving patients' use of topical ocular medications.

Keywords: glaucoma, administration, compliance, aid, drop chart

\section{Introduction}

Glaucoma is a progressive optic neuropathy caused by the death of the retinal ganglion cells and is currently the third cause of blindness in the world after refractive error and cataract. A major risk factor for glaucoma is high intraocular pressure (IOP), with clinicians aiming to reduce it by using various IOP-lowering agents (miotics, $\beta$-blockers, prostaglandin analogs, $\alpha$-agonists, carbonic anhydrase inhibitors, and epinephrine derivatives) or surgical alternatives (trabeculoplasty, trabeculectomy with or without insertion of various drainage tubes). The aim of these therapeutic approaches is to decrease aqueous humor production and increase the trabecular meshwork or uveoscleral outflow. Medical treatment for glaucoma has been extensively evaluated and assessed for efficacy in studies and trials. However, these studies do not assess compliance, an issue that is one of the major factors for failing treatment. ${ }^{1-6}$ In ophthalmology, noncompliance with eye drop therapy is a well-recognized problem, with $80 \%$ of the patients administering their own eye drops, ${ }^{7}$ using various techniques
Correspondence: Georgios Vakros Department of Ophthalmology, Queen's Hospital, Rom Valley Way, Romford RM7 OAG, Essex, UK

Tel +44I708435000

Email georgios.vakros@nhs.net 
and methods. ${ }^{8-11}$ This can potentially result in treatment failure if the method used is not appropriate, ${ }^{8}$ and due to the asymptomatic nature of glaucoma, good drop administration technique and long-term compliance are crucial in order to limit disease progression.

In the last 2 decades, researchers and clinicians have looked into ways of improving compliance with the use of compliance aids, audiovisual (AV) reminders, and more recently, smartphone applications. However, these devices are targeted toward administration, without taking into consideration patient education. Therefore, we developed the eye drop chart (EDC) tool: a novel educational aid that serves as a reminder for eye drop administration and overall compliance with ocular treatments. The aim of this pilot study was to assess the current practices and whether the use of EDC can improve compliance and administration of eye drops prescribed for patients suffering with glaucoma.

\section{Materials and methods}

This prospective, cross-sectional study was conducted in Bath Royal United Hospital, Bath, England. We enrolled 31 subjects who attended the glaucoma specialist clinic and were diagnosed with either glaucoma or ocular hypertension. All participants were receiving treatment in the form of one or more IOP-lowering eye drops to one or both eyes. Subjects suffering with a cognitive impairment were excluded from the recruitment, as they did not fulfill the informed consent criteria. In addition, six subjects were excluded, as the questionnaires were not adequately completed. Demographic data collected included age, sex, employment, social circumstances, ocular pathology for which drops are administered, and other ocular comorbidities, as well as drop administration (duration, frequency, number of drops, storage, person administering, and number of missed drops). Finally, informed consent was obtained from all participants prior to enrollment, and the protocol followed the tenets of the Declaration of Helsinki. The local Institutional Review Board approved the conduction of this study.

The EDC was designed and developed by the authors of this study (Figure 1) and was administered to the patients recruited alongside a cover letter outlining the aim of the project, an educational leaflet on drop administration, and two questionnaires (one to be completed in clinic prior to the use of EDC and the other 1 month post-EDC use).

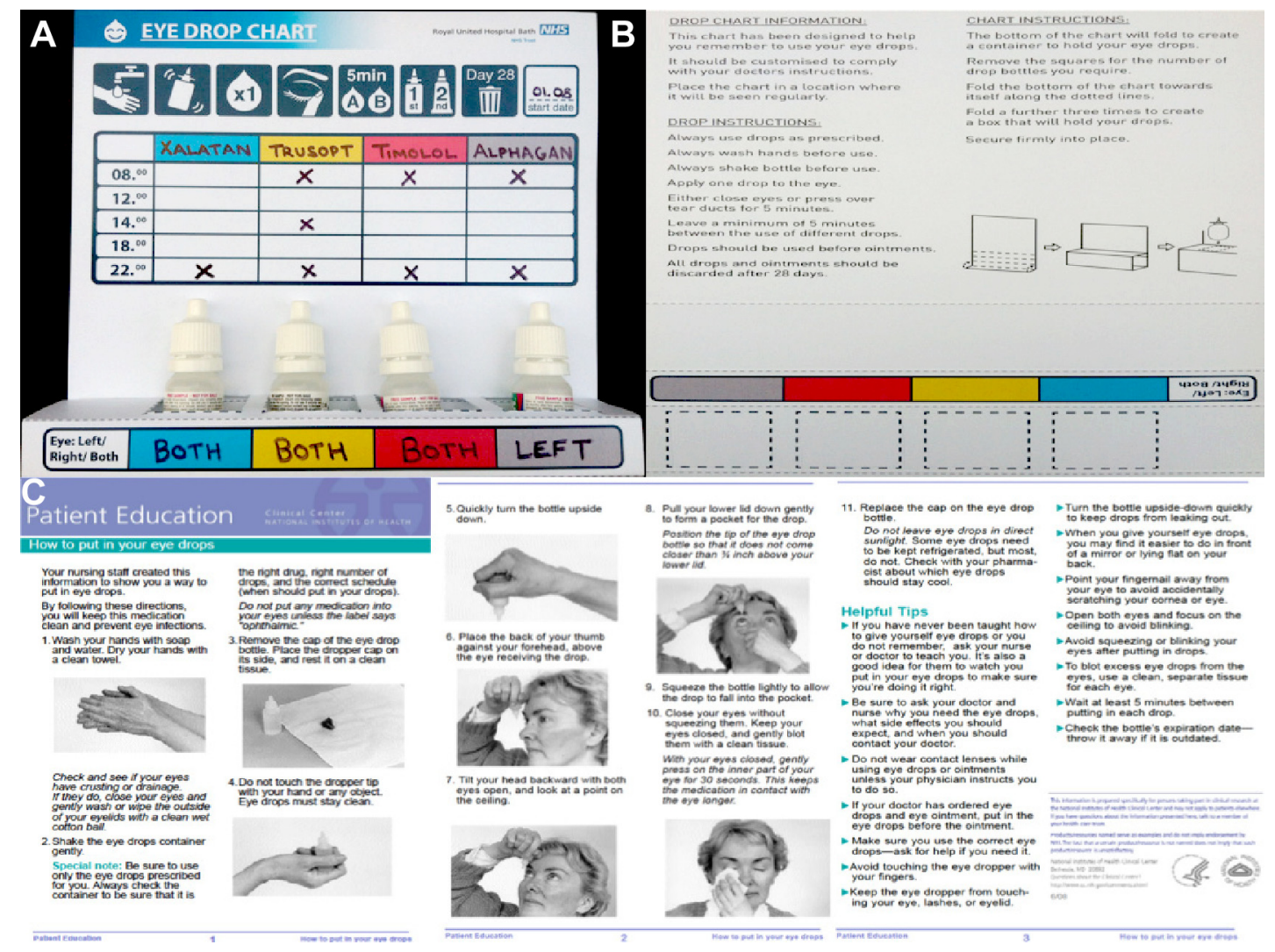

Figure I The eye drop chart.

Notes: At the front the various eye drops with their frequencies and visual explanations are given (A). At the back there are detailed instructions about the eye drop chart and how to use it as well as instructions about drop instillation (B) along with a detailed educational leaflet of correct eye drop administration technique (C). 
Table I Questionnaire regarding the use of EDC - pre- and posttest

\begin{tabular}{ll}
\hline Questions & Answers \\
\hline How often do you remember & Every time \\
to wash your hands before using & Often \\
your eye drops? & Once a week or less \\
How often do you remember & Every time \\
to shake the bottle before use? & Often \\
& Once a week or less \\
How often do you manage to administer & Every time \\
one eye drop to the eye? & Often \\
& Once a week or less \\
How often does the bottle tip touch & Every time \\
the eye when using your eye drops? & Often \\
& Once a week or less \\
How often do the drops miss the eye? & Every time \\
& Often \\
How often do you close the eye or press & Once a week or less \\
on the tear ducts after using drops? & Every time \\
& Often \\
How long do you do this for? & Once a week or less \\
& NA - no \\
How often do you remember to leave & $<$ I minute \\
5 minutes between different drops? & I-5 minutes \\
If you use drops and ointments, how often & Every time \\
do you remember to use the drops first? & Often \\
& Once a week or less \\
bottle after 28 days of use? & Every time \\
& Often \\
\hline & Once a week or less \\
& Every time \\
& Often \\
& Once a week or less \\
&
\end{tabular}

Abbreviations: EDC, eye drop chart; NA, not answered.

Both questionnaires were identical (Table 1), with the only difference being a set of reflective questions regarding the EDC (Table 2).

\section{Statistical analysis}

Responses to the pre- and post-questionnaires were summarized as frequency (percentage) and were compared using the chi-square test or Fisher's exact test, as appropriate.

\section{Statement of ethics}

We certify that all applicable institutional and governmental regulations concerning the ethical use of human volunteers were followed during this research.

\section{Results}

Twenty-five patients were included in the analysis; the mean age of the study population was $75 \pm 11$ years (range, 45-90 years). Table 3 shows the demographic and clinical characteristics of the included patients.
Table 2 Reflective questions following the trial of EDC

\begin{tabular}{ll}
\hline Questions & Answers \\
\hline Did you find the EDC useful? & Yes \\
& Maybe \\
& No \\
What did you like about the EDC? & Everything \\
& Instructions/reminder \\
& Bright \\
& Nothing \\
What did you dislike about the EDC? & Nothing \\
& Purposeless \\
Would you continue using the EDC? & Shape/size/color \\
& Yes \\
Would you recommend the EDC & Maybe \\
to a friend? & No \\
& Yes \\
Do you feel the EDC has improved & Maybe \\
your drop administration techniques & No \\
and compliance? & Yes \\
How often did you feel you forgot your & Maybe \\
drops while using the EDC? & No \\
& Never \\
Did you encounter any other issues & Rarely \\
regarding drop use? & Weekly \\
\hline
\end{tabular}

Abbreviation: EDC, eye drop chart.

Regarding eye drops use, twelve (48\%) patients had been using eye drops for more than 5 years in comparison to ten $(40 \%)$ patients who have been using them for less than 5 years. In addition, twelve (48\%) patients were using only one topical eye drop, eleven (44\%) patients were on two drops, and two (8\%) patients were on three different drops. Of these, $16(64 \%)$ patients were using only one drop for glaucoma, while nine (36\%) subjects were on dual therapy. There were no patients on three different drops for glaucoma.

We further looked into our patients' attitudes toward their eye drops and specifically about the frequency of instillation and the missed doses. Fourteen (56\%) patients reported that they instill eye drops only once a day, while eleven (44\%) more than once. Additionally, nine (36\%) patients reported they never missed their eye drops prior to the chart, while eleven (44\%) and five (20\%) reported that they missed their drops rarely and once weekly or more, respectively. Moreover, our study revealed that $22(88 \%)$ patients self-administered their eye drops, while three $(12 \%)$ had their eye drops instilled by others. Finally, regarding storage of the eye drops, seven (28\%) patients stored their eye drops in the bathroom, while nine (36\%) and four (16\%) stored them by their bedside cabinet and fridge, respectively. Five $(20 \%)$ patients stored their drops in various places other the aforementioned. It was evident that those who stored their 
Table 3 Demographics and clinical characteristics

\begin{tabular}{ll}
\hline & Number of subjects (\%) \\
\hline Sex & $13(52)$ \\
Fale & $12(48)$ \\
Age (years) & \\
$<69$ & $9(36)$ \\
$69-85$ & $10(40)$ \\
$85+$ & $6(24)$ \\
Employment & \\
Working & $4(16)$ \\
Retired/unemployed & $21(84)$ \\
Living circumstances & \\
Alone & $7(28)$ \\
Partner & $15(60)$ \\
Family & $3(12)$ \\
Glaucoma type & $12(48)$ \\
Primary open-angle glaucoma & $5(20)$ \\
Normal tension glaucoma & $1(4)$ \\
Ocular hypertension & $2(8)$ \\
Pigment dispersion glaucoma & $1(4)$ \\
Narrow-angle glaucoma & $4(16)$ \\
Not specified & $21(84)$ \\
Comorbidities & $2(8)$ \\
None & $2(8)$ \\
Dry eye & Age-related macular degeneration
\end{tabular}

drops in the fridge or various other places reported higher frequency of missed eye drops than those who opted for the bathroom or bedroom.

We further wanted to evaluate the effectiveness of the EDC, based on the aforementioned criteria regarding poor compliance and complications in relation to eye drops. Overall, our results demonstrated that the EDC improved the administration of eye drops in our cohort (Table 4). It was evident that the subjects who used the EDC had a significant improvement in hand hygiene $(P=0.029)$ and shaking the bottle prior to use $(P=0.001)$. In addition, the chart helped our patients significantly in remembering to apply tear duct occlusion $(P=0.015)$.

We wanted to examine the views our participants held about the EDC. Overall, the EDC was well accepted by the participants, with 12 (48\%) liking everything about it and 16 (64\%) disliking nothing about it. In particular, they liked the instructions (eleven subjects [44\%]) and the brightness of the chart (one patient [4\%]). One patient (4\%) did not like anything about the chart, feeling that it was without purpose. Finally, eight patients (32\%) suggested that the esthetics such as the shape, size, and color of the EDC could be improved. With regard to the use of EDC, sixteen participants (64\%) found the chart useful, and out of those, ten (40\%) would continue using it, while all of them would recommend it to another patient. Moreover, fifteen subjects (60\%) admitted that EDC helped them with the delivery of their eye drops and fourteen patients (56\%) reported that it improved their compliance with the medications. The EDC assisted them in not missing eye drops, with twenty three patients (92\%) replying that they never or rarely missed eye drops instillation when using it.

\section{Discussion}

The results of this study highlighted the well-recognized issue of compliance among glaucoma patients and recommended a different way for it to improve. As far as we are concerned, this is the first ophthalmic study that looked into improving compliance and educating the patients simultaneously. Robin, in his review about compliance, concluded that to improve it, three areas need to be targeted: educational barriers, administration challenges, and individual variation. ${ }^{12}$ Education is a key factor in ensuring patients use their drops effectively, and providing a thorough understanding of the condition for which the medication has been prescribed can highlight the importance of complying with the treatment. When patients know what they are working toward, it can provide motivation to encourage them remember to take their eye drops. ${ }^{13}$ The idea of EDC was to eliminate mostly the administration challenges and individual variation by instructing patients how to administer their eye drops with the use of written instructions and illustrations, thus minimizing individual patient variation by following a self-administration method.

Several studies have looked into the association between patients and therapy factors such as age, sex, marital status, living situation, as well as the duration of treatment, dosing frequency, and compliance with medications. Age and sex of the patients do not seem to influence compliance. ${ }^{14}$ However, the marital status and whether they live with other family members do play a role. Patients who were married or lived with their partner/family members seem to be better in taking their medications. ${ }^{15-17}$ Kass et $\mathrm{al}^{7}$ reported that $20.6 \%$ of patients have their drops administered by others. In our cohort, eighteen (72\%) patients were not alone at home, and overall, only three (12\%) had their drops administered by others. Regarding the duration and frequency of treatment, it has been extensively shown that the longer the duration or the higher the frequency of administration, the worse the compliance. ${ }^{18-21}$ In our study, ten (40\%) patients had been longer than 5 years on treatment and eleven (44\%) subjects were administering their drops more than once a day. 
Table 4 Comparison of pre- and post-EDC results of steps taken during administration process of eye drops

\begin{tabular}{|c|c|c|c|}
\hline & Pre-EDC subjects (\%) & Post-EDC subjects (\%) & $P$-value \\
\hline \multicolumn{4}{|l|}{ Wash hands before } \\
\hline Every time & $16(64)$ & $23(92)$ & \multirow[t]{3}{*}{$0.029 *$} \\
\hline Often & $7(28)$ & I (4) & \\
\hline Once a week or less & $2(8)$ & I (4) & \\
\hline \multicolumn{4}{|l|}{ Shake bottle before } \\
\hline Every time & $10(40)$ & $21(84)$ & \multirow[t]{3}{*}{$0.001 *$} \\
\hline Often & $4(16)$ & $3(12)$ & \\
\hline Once a week or less & II (44) & I (4) & \\
\hline \multicolumn{4}{|l|}{ One drop in each eye } \\
\hline Every time & $16(64)$ & $16(64)$ & \multirow[t]{3}{*}{0.438} \\
\hline Often & $9(36)$ & $7(28)$ & \\
\hline Once a week or less & $0(0)$ & $2(8)$ & \\
\hline \multicolumn{4}{|l|}{ Bottle tip touch } \\
\hline Every time & $0(0)$ & $0(0)$ & \multirow[t]{3}{*}{0.999} \\
\hline Often & $4(16)$ & $5(20)$ & \\
\hline Once a week or less & $21(84)$ & $20(80)$ & \\
\hline \multicolumn{4}{|l|}{ Miss the eye } \\
\hline Every time & $0(0)$ & $0(0)$ & \multirow[t]{3}{*}{0.06} \\
\hline Often & $8(32)$ & $5(20)$ & \\
\hline Once a week or less & $17(68)$ & $20(80)$ & \\
\hline \multicolumn{4}{|l|}{ Tear ducts occlusion } \\
\hline Every time & II (44) & $18(72)$ & \multirow[t]{3}{*}{$0.015^{*}$} \\
\hline Often & $3(12)$ & $5(20)$ & \\
\hline Once a week or less & II (44) & $2(8)$ & \\
\hline \multicolumn{4}{|c|}{ Duration of duct occlusion } \\
\hline$N A-$ no & $19(76)$ & $10(40)$ & \multirow[t]{3}{*}{$0.035^{*}$} \\
\hline$<1$ minute & $3(12)$ & $7(28)$ & \\
\hline $\mathrm{I}-5$ minutes & $3(12)$ & $8(32)$ & \\
\hline \multicolumn{4}{|l|}{5 minutes between drops } \\
\hline Every time & $7(28)$ & $6(24)$ & \multirow[t]{3}{*}{0.999} \\
\hline Often & I (4) & $\mathrm{I}(4)$ & \\
\hline Once a week or less & $17(68)$ & $18(72)$ & \\
\hline \multicolumn{4}{|c|}{ Order in use drops then ointment } \\
\hline Every time & I (4) & $2(8)$ & \multirow[t]{3}{*}{0.999} \\
\hline Often & $0(0)$ & $0(0)$ & \\
\hline Once a week or less & $24(96)$ & $23(92)$ & \\
\hline \multicolumn{4}{|l|}{ Monthly disposal of bottle } \\
\hline Every time & $17(68)$ & $23(92)$ & \multirow[t]{3}{*}{0.09} \\
\hline Often & $2(8)$ & $\mathrm{I}(4)$ & \\
\hline Once a week or less & $6(24)$ & I (4) & \\
\hline \multicolumn{4}{|l|}{ Missed drops } \\
\hline Never & $9(36)$ & $12(48)$ & \multirow[t]{3}{*}{0.474} \\
\hline Rarely & II (44) & II (44) & \\
\hline Weekly & $5(20)$ & $2(8)$ & \\
\hline
\end{tabular}

Note: *, $P<0.05$.

Abbreviations: EDC, eye drop chart; NA, not answered.

According to Zimmerman et al, ${ }^{10}$ the ideal technique for drop instillation involves creating a pocket in the lower eyelid by pulling it away from the eye, then applying one drop to the pocket created. Following drop administration, the eye should be closed or pressure applied to the tear ducts with a finger (a technique known as punctal occlusion) for 1-2 minutes. This increases the ocular contact time and medication efficacy as well as limits the systemic absorption and secondary potential adverse effects of the medication. A 5-minute window is required between instillation of different eye drops, and drops should precede any ointments used. Problems such as lid or ocular touch, missing the eye, or flooding the eye with drops have been reported. A study by Sleath et $\mathrm{al}^{22}$ found that $44 \%$ of patients reported regularly missing the eye during attempted drop application. A further study by Stone et $\mathrm{al}^{23}$ found that when observing drop instillation, less 
than one-third were performed adequately, with 17\%-25\% unable to successfully administer the medication to the eye as desired. A qualitative study into glaucoma adherence by Lacey et $\mathrm{al}^{24}$ found that only a small percentage of the participants had received any guidance with respect to effective administration, and subsequently relied on the medication instruction manual, often considered difficult to read, or confusing as it conflicted with information obtained from other sources, eg, Internet, pharmacists, or other patients. The EDC helped significantly our participants with the correct administration of eye drops, and its format helps the users to have clear and concise instructions.

Recently, there have been efforts to develop applications for smartphones in order to help patients with monitoring their health condition as well as medication compliance. One study by Mira et $\mathrm{al}^{25}$ piloted a compliance app (ALICE) for elderly patients taking multiple medications. They concluded that patients felt ALICE improved their independence in managing their medications and demonstrated that experience with information and communication technologies is not required in order to use the application. Additionally, other studies utilized short messaging service (SMS) reminder technology for improving medications compliance. The only glaucoma-specific study carried out by Ho et $\mathrm{al}^{26}$ looked into AV aids and how they can help improve compliance by showing the value of reminders in glaucoma. By comparison, we believe that the EDC is a very good compliance method because it does not depend on information and communication technology literacy and is accessible to everyone due to its low cost, important issues when considering the age and number of glaucoma patients.

However, the study design does have limitations. First, the majority of the data were collected using a unique questionnaire for this study, thus not previously validated. In addition, it is possible that bias might have been introduced due to the setting of the study, ie, the glaucoma clinic. Patients could have felt under pressure to perform as they were attending the clinic and aware that they were somewhat "observed" by the researchers with variable impact on their performance. This makes it difficult to marry the EDC use with a reduced IOP. Therefore, more emphasis was placed on the subjective feedback received. Furthermore, we did not examine whether the patients were using compliance aids, which could have influenced our results. Although none of the patients enrolled in this study volunteered that they were already using an aid, this should have been clarified at the outset of the study to enable the results to be analyzed separately or excluded. Patients needed to be literate. Finally, the sample size of the study also limits its significance.

To further evaluate the validity of the EDC, another study with a larger sample size is required. The sample group would be compared alongside a control group that is not using the EDC. If carried out in a longitudinal manner, not only could long-term compliance with the EDC be assessed, but also a plot of the IOP, optic nerve head, and field progression could be drawn between the test and control groups. Furthermore, it would be interesting to draw a comparison between patients new to drop treatments and those familiar with the practice. A discrepancy in the knowledge base and a steeper learning curve within the new patient group could result in a seemingly greater response.

Despite these limitations, the results of this pilot study are still very encouraging, and EDC appears to be fulfilling its intended purpose by encouraging improvement in drop administration techniques through education and improved compliance through acting as a memory aid.

The EDC could prove to be a very cost-effective tool, resulting in improved glaucoma control and reduction in the overall sequelae of the disease, subsequently reducing the need for such regular clinical follow-up.

\section{Acknowledgments}

We thank all patients who took the time to participate in this pilot study.

\section{Disclosure}

There are no proprietary interests, and no research funding has been sought. This work was previously presented as a poster at the Faculty of Medical Leadership and Management Conference in 2013. The authors report no other conflicts of interest in this work.

\section{References}

1. Kass MA, Meltzer DW, Gordon M, Cooper D, Goldberg J. Compliance with topical pilocarpine treatment. Am J Ophthalmol. 1986; 101:515-523.

2. Winfield AJ, Jessiman D, Williams A, Esakowitz L. A study of the causes of non-compliance by patients prescribed eyedrops. Br J Ophthalmol. 1990; 74:477-480.

3. Granstrom PA. Glaucoma patients not compliant with their drug therapy: clinical and behavioural aspects. Br J Ophthalmol. 1982;66:464-470.

4. Lu VH, Goldberg I, Lu CY. Use of glaucoma medications: state of the science and directions for observational research. Am J Ophthalmol. 2010;150:569-574.

5. Stryker JE, Beck AD, Primo SA, et al. An exploratory study of factors influencing glaucoma treatment adherence. J Glaucoma. 2010;19: 66-72.

6. Tsai JC, McClure CA, Ramos SE, Schlundt DG, Pichert JW. Compliance barriers in glaucoma: a systematic classification. J Glaucoma. 2003;12:393-398. 
7. Kass MA, Hodapp E, Gordon M, Kolker AE, Goldberg I. Part I. Patient administration of eyedrops: interview. Ann Ophthalmol. 1982; 14:775-779.

8. Gupta R, Patil B, Shah BM, Bali SJ, Mishra SK, Dada T. Evaluating eye drop instillation technique in glaucoma patients. J Glaucoma. 2012;21(3):189-192.

9. Fraunfelder FT. Extraocular fluid dynamics: how best to apply topical ocular medication. Trans Am Ophthalmol Soc. 1976;74:457-487.

10. Zimmerman TJ, Kooner KS, Kandarakis AS, Ziegler LP. Improving the therapeutic index of topically applied ocular drugs. Arch Ophthalmol. 1984;102:551-553.

11. Tsai T, Robin AL, Smith JP III. An evaluation of how glaucoma patients use topical medications: a pilot study. Trans Am Ophthalmol Soc. 2007;105:29-35.

12. Robin A. Beyond compliance: getting the drops in [Online]. Rev Ophthalmol. 2010. Available from: http://www.revophth.com/content/d/ glaucoma/c/22759/. Accessed June 24, 2013.

13. Abelson MB, Torkildsen G, Fink K. Taking steps towards better compliance [Online]. Rev Ophthalmol. 2006. Available from: http://www. reviewofophthalmology.com/content/d/therapeutic_topics/i/1308/ c/25184/. Accessed June 24, 2013.

14. Jin J, Sklar GE, Oh VMS, Li SC. Factors affecting therapeutic compliance: a review from the patient's perspective. Ther Clin Risk Manag. 2008;4(1):269.

15. Cooper C, Carpenter I, Katona C, et al. The AdHOC Study of older adults' adherence to medication in 11 countries. Am J Geriatr Psychiatry. 2005;13(12):1067-1076.

16. Kaona FA, Tuba M, Siziya S, Sikaona L. An assessment of factors contributing to treatment adherence and knowledge of TB transmission among patients on TB treatment. BMC Public Health. 2004;4(1):68.
17. Yavuz A, Tuncer M, Erdoğan O, et al. Is there any effect of compliance on clinical parameters of renal transplant recipients? Transplant Proc. 2004;36(1):120-121.

18. Claxton AJ, Cramer J, Pierce C. A systematic review of the associations between dose regimens and medication compliance. Clin Ther. 2001;23(8):1296-1310.

19. Dhanireddy KK, Maniscalco J, Kirk AD. Is tolerance induction the answer to adolescent non-adherence? Pediatr Transplant. 2005;9(3): 357-363.

20. Gascón JJ, Sánchez-Ortuño M, Llor B, Skidmore D, Saturno PJ. Why hypertensive patients do not comply with the treatment Results from a qualitative study. Fam Pract. 2004;21(2):125-130.

21. Iskedjian M, Einarson TR, MacKeigan LD, et al. Relationship between daily dose frequency and adherence to antihypertensive pharmacotherapy: evidence from a meta-analysis. Clin Ther. 2002;24(2):302-316.

22. Sleath B, Robin AL, Covert D, Byrd JE, Tudor G, Svarstad B. Patient reported behavior and problems in using glaucoma medications. Ophthalmology. 2006;113:431-436.

23. Stone JL, Robin AL, Novack GD, Covert DW, Cagle GD. An objective evaluation of eyedrop instillation in patients with glaucoma. Arch Ophthalmol. 2009;127:732-736.

24. Lacey J, Cate H, Broadway DC. Barriers to adherence with glaucoma medications: a qualitative research study. Eye. 2009;23:924-932.

25. Mira JJ, Navarro I, Botella F, et al. A Spanish pillbox app for elderly patients taking multiple medications: randomized controlled trial. J Med Internet Res. 2014;16(4):e99.

26. Ho LY, Camejo L, Kahook MY, Noecker R. Effect of audible and visual reminders on adherence in glaucoma patients using a commercially available dosing aid. Clin Ophthalmol. 2008;2(4):769-772.
Clinical Ophthalmology

\section{Publish your work in this journal}

Clinical Ophthalmology is an international, peer-reviewed journa covering all subspecialties within ophthalmology. Key topics include: Optometry; Visual science; Pharmacology and drug therapy in eye diseases; Basic Sciences; Primary and Secondary eye care; Patient Safety and Quality of Care Improvements. This journal is indexed on

Submit your manuscript here: http://www.dovepress.com/clinical-ophthalmology-journal

\section{Dovepress}

PubMed Central and CAS, and is the official journal of The Society of Clinical Ophthalmology (SCO). The manuscript management system is completely online and includes a very quick and fair peer-review system, which is all easy to use. Visit http://www.dovepress.com/ testimonials.php to read real quotes from published authors. 